\title{
Analgesic use during pregnancy and risk of infant leukaemia: A Children's Oncology Group study
}

\author{
S Ognjanovic ${ }^{*, 1,2}$, C Blair', LG Spector ${ }^{1,2}$, LL Robison ${ }^{3}$, M Roesler' $^{1}$ and JA Ross ${ }^{1,2}$ \\ 'Division of Pediatric Epidemiology and Clinical Research, University of Minnesota, 420 Delaware Street SE, MMC 422, Minneapolis, MN 55455, USA; \\ ${ }^{2}$ Masonic Cancer Center, University of Minnesota, 425 E River Road, 554 MCRB, Minneapolis, MN 55455, USA; ${ }^{3}$ Department of Epidemiology and \\ Cancer Control, St Jude Children's Research Hospital, 262 Danny Thomas Place, MS-735, Memphis, TN 38I 05, USA
}

BACKGROUND: Infant leukaemia is likely initiated in utero.

METHODS: We examined whether analgesic use during pregnancy was associated with risk by completing telephone interviews of the mothers of 44I infant leukaemia cases and 323 frequency-matched controls, using unconditional logistic regression.

RESULTS: With the exception of a reduced risk for infant acute myeloid leukaemias with non-aspirin non-steroidal anti-inflammatory drugs (NSAID) use early in pregnancy (odds ratios =0.60; confidence intervals: 0.37-0.97), no statistically significant associations were observed for aspirin, non-aspirin NSAIDs, or acetaminophen use in early pregnancy or after knowledge of pregnancy. CONCLUSION: Overall, analgesic use during pregnancy was not significantly associated with the risk of infant leukaemia. British Journal of Cancer (20I I) I 04, 532-536. doi:I0.1038/sj.bjc.6606046 www.bjcancer.com Published online 14 December 2010

(c) 20II Cancer Research UK

Keywords: epidemiology; infants; leukaemia; analgesics

Infant leukaemia, diagnosed in the first year of life, is rare, with an incidence rate of 39.9 per million in the United States (Linabery and Ross, 2008). Approximately $60 \%$ of infant acute myeloid leukaemias (AML) and $80 \%$ of infant acute lymphoblastic leukaemias (ALL) involve rearrangement of the $M L L$ gene (Ross and Spector, 2006), which are rare in older children and adults. Evidence of an in utero origin for some infant leukaemia comes from molecular studies, in which $M L L$ translocations identified in leukaemia cells at diagnosis were also found in Guthrie cards collected shortly after birth (Gale et al, 1997; Greaves and Wiemels, 2003). Further, studies of twins with leukaemia revealed the presence of identical $M L L$ rearrangements, suggesting that the initiating event occurs in utero in one twin and is transferred to the other twin via shared placental circulation (Greaves et al, 2003). The only firmly established risk factors for childhood leukaemia are in utero exposure to X-rays, specific genetic syndromes, such as Down's syndrome, and high birth weight (reviewed in Ross and Spector (2006)), which together explain only a very small proportion of leukaemia cases.

Regular use of aspirin or other non-steroidal anti-inflammatory drugs (NSAIDs) has been associated with a reduced risk of many adult cancers (Gonzalez-Perez et al, 2003; Bosetti et al, 2006; Elwood et al, 2009). Two studies of adult leukaemia suggested a protective effect with aspirin (Kasum et al, 2003; Weiss et al, 2006), but no effect with non-aspirin NSAIDs, and a possible increased risk with acetaminophen (Weiss et al, 2006). For childhood leukaemia, results are inconsistent with regard to maternal analgesic use (Wen et al, 2002; Shaw et al, 2004; Schuz et al,

*Correspondence: Dr S Ognjanovic; E-mail: ognja00I@umn.edu Received 24 September 2010; revised 8 November 2010; accepted 17 November 20 I0; published online 14 December 2010
2007), although many of these drugs are known to cross the placenta (Alano et al, 2001).

Given the paucity of risk factors identified for infant leukaemia, the strong evidence of an in utero origin, and the potential for possible effects on the developing fetus, we examined nonprescription maternal analgesic use and the risk of infant leukaemia.

\section{MATERIALS AND METHODS}

Details for recruitment and data collection have been reported previously (Spector et al, 2005; Puumala et al, 2009, 2010). Cases comprised infants diagnosed with or treated for ALL or AML in the first year of life at one of the Children's Oncology Group (COG) institutions in the United States or Canada between January 1996 and October 2002 (phase I) and January 2003 and December 2006 (phase II). Additional eligibility criteria included the availability of a Spanish-speaking (phase II only) or English-speaking biological mother for telephone interview, and the absence of Down's syndrome. During phase I of recruitment, 348 cases were confirmed as eligible and interviews were completed for 240 $(69 \%)$. For phase II, 345 potentially eligible cases were identified and 203 (59\%) completed interviews.

During phase I of recruitment, controls were identified using random digit dialling, and frequency matched to cases on year of birth. Interviews were completed for 254 of 430 potentially eligible controls (59\% field response rate). In phase II, controls were identified through a sample of state birth registries. Controls were frequency matched to cases on year of birth and region of residence based on the distribution of cases enrolled during phase I. Interviews were completed for 71 out of 267 potentially eligible controls ( $27 \%$ field response rate). The two control groups were 
found to be similar based on both maternal and infant characteristics (Puumala et al, 2009), and thus were combined into one control group for this analysis.

Informed consent was obtained from all participants. Information on maternal and infant characteristics was collected through computer-assisted telephone interviews with the biological mother. Analgesic questions included maternal use of aspirin, acetaminophen and non-aspirin NSAIDs, both before and after knowledge of pregnancy, including the frequency of use during these two time periods. The frequency of use categories before knowledge of pregnancy included fewer than 5 times, 5-25 times, and more than 25 times. For the period after knowledge of pregnancy through the end of the pregnancy, the categories were less than 10 times, $10-50$ times, and greater than 50 times. Detailed reports on leukaemia cell cytogenetics and molecular abnormalities were obtained for cases and included leukaemia subtype (ALL, AML) and $M L L$ gene translocation status $(M L L+, M L L-$, undetermined). Data on analgesic use during pregnancy were missing for two cases and one control. Few women reported using any type of analgesic more than 25 times before knowledge of pregnancy or more than 50 times after knowledge of pregnancy, which precluded examining frequency of use. Instead, for each type of analgesic,

Table I Selected characteristics according to infant leukaemia status ${ }^{a}$

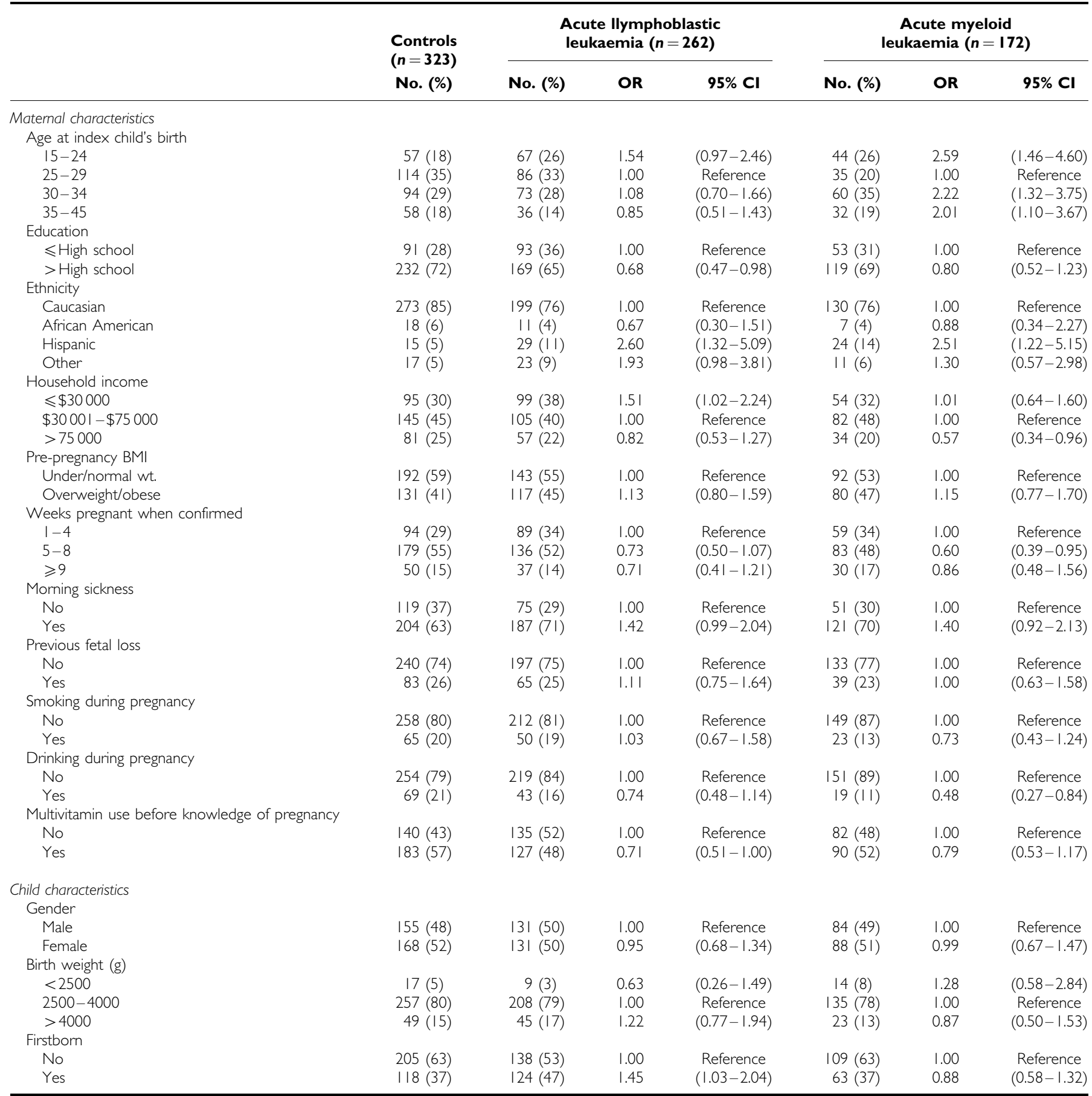

Abbreviations: $\mathrm{Cl}=$ confidence interval; $\mathrm{OR}=$ odds ratio. ${ }^{2}$ Logistic regression models adjusted for the matching factor and index child's year of birth (continuous). Values may not sum to the total number of cases and controls owing to missing values. 
we created two variables: one for any use during the specified period and a second to indicate regular use (more than 5 times before knowledge of pregnancy or more than 10 times after knowledge of pregnancy).

Statistical analyses were carried out using SAS version 9.2 (SAS Institute, Cary, NC, USA). The possible association of analgesic use and the risk of infant acute leukaemia was evaluated using unconditional logistic regression. Odds ratios (OR) and 95\% confidence intervals $(95 \% \mathrm{CI})$ were calculated. All models were adjusted for the matching factor, year of birth. In addition, maternal characteristics listed in Table 1 were evaluated as potential confounders and included in the final regression model if they materially altered any of the analgesic variable estimates. All statistical tests were two-sided. Analyses were conducted separately by leukaemia subtype (ALL, AML), and $M L L$ status $(M L L+, M L L-)$.

\section{RESULTS}

Selected characteristics of 434 infant leukaemia cases (262 ALL, 172 AML) and 323 controls are shown in Table 1. Cases and controls were similar with respect to previous fetal loss, smoking during pregnancy, pre-pregnancy BMI, and infant gender and birth weight. However, compared with mothers of controls, mothers of cases were more likely to be younger (ALL), of Hispanic ethnicity (ALL, AML), of lower income (ALL, AML), and to report morning sickness (ALL). Case mothers were less likely

Table 2 Association of maternal pain reliever use during pregnancy and the risk of infant leukaemia ${ }^{a}$

\begin{tabular}{|c|c|c|c|c|c|c|c|}
\hline & \multirow[b]{2}{*}{$\mathbf{N}(\%)$} & \multicolumn{3}{|c|}{ Acute lymphoblastic leukaemia } & \multicolumn{3}{|c|}{ Acute myeloid leukaemia } \\
\hline & & $\mathbf{N}(\%)$ & OR & $95 \% \mathrm{Cl}$ & $N(\%)$ & OR & $95 \% \mathrm{Cl}$ \\
\hline \multicolumn{8}{|c|}{ Before knowledge of pregnancy } \\
\hline \multicolumn{8}{|c|}{ Any use } \\
\hline No & $287(89.4)$ & $236(90.4)$ & 1.00 & Reference & $158(94.6)$ & 1.00 & Reference \\
\hline Yes & $34(10.6)$ & $25(9.6)$ & 1.03 & $0.58-1.85$ & $9(5.4)$ & 0.55 & $0.24-1.26$ \\
\hline Yes & $12(3.8)$ & $8(3.1)$ & 1.25 & $0.48-3.31$ & $4(2.4)$ & 0.80 & $0.22-2.97$ \\
\hline \multicolumn{8}{|c|}{ After knowledge of pregnancy } \\
\hline \multicolumn{8}{|c|}{ Any use } \\
\hline No & $309(96.3)$ & $252(96.6)$ & 1.00 & Reference & $163(97.0)$ & 1.00 & Reference \\
\hline Yes & $12(3.7)$ & $9(3.5)$ & 1.21 & $0.48-3.05$ & $5(3.0)$ & 0.96 & $0.32-2.92$ \\
\hline \multicolumn{8}{|c|}{ Regular use $\mathrm{b}^{\mathrm{b}}$} \\
\hline No & $314(97.8)$ & $255(97.7)$ & 1.00 & Reference & $166(98.8)$ & 1.00 & Reference \\
\hline No & $219(68.2)$ & $168(64.9)$ & 1.00 & Reference & $130(77.4)$ & 1.00 & Reference \\
\hline Yes & $102(31.8)$ & $91(35.1)$ & 1.15 & $0.80-1.67$ & $38(22.6)$ & 0.60 & $0.37-0.97$ \\
\hline \multicolumn{8}{|c|}{ Regular use $\mathrm{b}^{\mathrm{b}}$} \\
\hline No & $293(91.3)$ & $231(89.2)$ & 1.00 & Reference & $158(94.1)$ & 1.00 & Reference \\
\hline Yes & $28(8.7)$ & $28(10.8)$ & 1.41 & $0.78-2.57$ & $10(6.0)$ & 0.68 & $0.29-1.59$ \\
\hline \multicolumn{8}{|c|}{ After knowledge of pregnancy } \\
\hline \multicolumn{8}{|c|}{ Any use } \\
\hline No & $292(91.0)$ & $232(88.9)$ & 1.00 & Reference & $158(94.1)$ & 1.00 & Reference \\
\hline Yes & $29(9.0)$ & $29(11.1)$ & 1.33 & $0.75-2.37$ & $10(6.0)$ & 0.81 & $0.36-1.83$ \\
\hline \multicolumn{8}{|c|}{ Regular use ${ }^{\mathrm{b}}$} \\
\hline No & $315(98.1)$ & $252(96.6)$ & 1.00 & Reference & $166(98.8)$ & 1.00 & Reference \\
\hline Yes & $6(1.9)$ & $9(3.5)$ & 1.94 & $0.64-5.93$ & $2(1.2)$ & 0.73 & $0.13-4.02$ \\
\hline \multicolumn{8}{|c|}{ Acetaminophen } \\
\hline Any us & & & & & & & \\
\hline No & $94(29.4)$ & 80 (30.7) & 1.00 & Reference & $57(33.9)$ & 1.00 & Reference \\
\hline Yes & $226(70.6)$ & |8| (69.4) & 1.03 & $0.70-1.53$ & $111(66.1)$ & 0.79 & $0.50-1.24$ \\
\hline Regular & & & & & & & \\
\hline No & $247(77.2)$ & 191 (73.2) & 1.00 & Reference & $137(8 \mid .6)$ & 1.00 & Reference \\
\hline Yes & $73(22.8)$ & $70(26.8)$ & 1.27 & $0.85-1.90$ & $31(18.5)$ & 0.77 & $0.46-1.30$ \\
\hline
\end{tabular}

Abbreviations: $\mathrm{Cl}=$ confidence interval; NSAIDs = non-steroidal anti-inflammatory drugs; OR =odds ratio. a Logistic regression models are adjusted for maternal age ( $15-24$, $25-29,30-34,35-45)$, race (white, black, Hispanic, other), alcohol consumption during pregnancy (yes/no), household income $(<\$ 30000, \$ 3000$ I $-\$ 75000,>\$ 75000)$, and index child's year of birth (continuous). 'Regular use of a pain reliever before and after knowledge of pregnancy is defined as $\geqslant 5$ and $\geqslant 10$ times, respectively. 
to have completed education beyond high school (ALL), initiated multivitamin use before knowledge of pregnancy (ALL), reported alcohol consumption during pregnancy (AML), and confirmed pregnancy before the third month (AML).

We also evaluated the distribution of cases and controls with regard to analgesic use across selected potential confounders for the two pregnancy periods (data not shown). Before knowledge of pregnancy, acetaminophen was the most commonly (63\%) used analgesic, followed by non-aspirin NSAIDs (31\%) and aspirin $(9 \%)$. Compared with non-regular users ( $\leqslant 5$ times), regular users were more likely to smoke during pregnancy and less likely to have completed education beyond high school or to report an annual household income greater than $\$ 75000$. Regular aspirin or nonaspirin NSAID users were more likely to be Caucasian and to drink during pregnancy, whereas regular acetaminophen users were less likely to use multivitamins before knowledge of pregnancy, compared with non-regular users. After knowledge of pregnancy, acetaminophen use increased $(69 \%)$, whereas the use of aspirin and non-aspirin NSAIDs decreased (3 and 9\%, respectively); only 19 case mothers and 13 control mothers used aspirin or nonaspirin NSAIDs regularly ( $\geqslant 10$ times).

Possible associations between infant leukaemia and maternal analgesic use, assessed both before and after knowledge of pregnancy, are shown in Table 2. There was no association between any use or regular use of aspirin, non-aspirin NSAIDs or acetaminophen with infant ALL, in either pregnancy period. However, for AML, there was a statistically significant or borderline significant reduced risk associated with any use of non-aspirin NSAIDs $(\mathrm{OR}=0.60, \mathrm{CI}: 0.37-0.97)$ and acetaminophen $(\mathrm{OR}=0.66, \mathrm{CI}: 0.43-1.01)$, respectively, but not with aspirin $(\mathrm{OR}=0.55$, CI: 0.24-1.26); regular use of each analgesic did not reflect further reduction in risk. These inverse associations were observed only before knowledge of pregnancy, whereas they were attenuated toward the null after knowledge of pregnancy.

We also examined whether associations were confined to particular MLL groups of ALL and AML (data not shown). Among ALL cases, 155 were $M L L+, 77 M L L-$, and 30 with undetermined $M L L$ status, whereas among AML cases there were $68 M L L+, 66$ $M L L-$, and 38 undetermined. For AML, the inverse association observed for non-aspirin NSAIDs and acetaminophen was confined to cases that did not have the $M L L$ gene rearrangement $(\mathrm{OR}=0.42, \mathrm{CI}: 0.20-0.88$, and $\mathrm{OR}=0.57, \mathrm{CI}: 0.32-1.02$, respectively), whereas ALL showed no association for either $M L L$ subgroup.

\section{DISCUSSION}

We evaluated the association between maternal analgesic use and the risk of infant leukaemia. Although our results suggest that acetaminophen and non-aspirin NSAID use may be inversely associated with infant AML when taken early in pregnancy, it should be noted that these estimates were attenuated when confined to regular use ( $\geqslant 5$ times). The inverse association was

\section{REFERENCES}

Alano MA, Ngougmna E, Ostrea Jr EM, Konduri GG (2001) Analysis of nonsteroidal antiinflammatory drugs in meconium and its relation to persistent pulmonary hypertension of the newborn. Pediatrics 107: 519-523

Bosetti C, Gallus S, La Vecchia C (2006) Aspirin and cancer risk: an updated quantitative review to 2005. Cancer Causes Control 17: 871-888

Elwood PC, Gallagher AM, Duthie GG, Mur LA, Morgan G (2009) Aspirin, salicylates, and cancer. Lancet 373: $1301-1309$

Gale KB, Ford AM, Repp R, Borkhardt A, Keller C, Eden OB, Greaves MF (1997) Backtracking leukemia to birth: identification of clonotypic gene fusion sequences in neonatal blood spots. Proc Natl Acad Sci USA 94: 13950 - 13954 confined to the subgroup containing no $M L L$ gene rearrangement. This subtype most closely resembles childhood AML diagnosed after the age of 1 year, when only $5 \%$ of AML cases present with $M L L$ gene rearrangements (Taki et al, 1996). We found no association between any of the analgesics studied and ALL risk.

Aspirin use had no effect on infant leukaemia risk in either pregnancy period. However, aspirin is not recommended during pregnancy, especially during the last trimester, although $10-30 \%$ of women may use aspirin in the first trimester before they are aware of their pregnancy (Werler et al, 1989; Kozer et al, 2002). In our study, aspirin was used by $10.5 \%$ of controls and $8.5 \%$ of cases before knowledge of pregnancy, and by $3.7 \%$ of controls and $3.3 \%$ of cases after knowledge of pregnancy.

Two out of three studies found no association between maternal analgesic use and risk of leukaemia in children $0-14$ years of age (Wen et al, 2002; Schuz et al, 2007). In contrast, one study reported a borderline significant two-fold increased risk of childhood ALL associated with prescription or over-the-counter anti-inflammatory drug use during pregnancy (Shaw et al, 2004). These three studies, however, included few women who used these medications during pregnancy. In addition, associations may have been diluted owing to broad medication groupings and few details on specific medications used.

Strengths and weaknesses of our study are relevant. This is the largest infant leukaemia study to date and included availability of $M L L$ gene status. Identification of cases through COG provided a nearly population-based study population, as COG institutions see $\sim 100 \%$ of leukaemia cases aged $0-4$ years (Ross et al, 1996). We evaluated different classes of analgesics, but not their doses. The small sample size for some subgroup analyses warrants caution in interpretation of the relevant associations. In particular, given the low frequency of aspirin use, especially after knowledge of pregnancy, we had limited power to evaluate aspirin effects. Recall bias is a concern in case-control studies, but it is unlikely that mothers with ALL infants would recall their exposures differently from mothers with AML. Further, the early age of onset helped to limit the recall period. There is also some concern with regard to selection bias. We found that use of analgesics varied by race, income, educational attainment, and smoking or alcohol consumption during pregnancy. Although we adjusted for maternal race, ethnicity, income, and alcohol consumption during pregnancy, residual confounding may remain.

In summary, this study found no significant association between the use of over-the-counter analgesics and risk of infant leukaemia.

\section{ACKNOWLEDGEMENTS}

This work was supported by NIH R01 CA79940, U10 CA13539, U10 CA98543, U1098413, the Children's Cancer Research Fund, Minneapolis, MN, and NIH P30 CA77588 (University of Minnesota Masonic Cancer Center shared resource: Health Survey Research Center).
Gonzalez-Perez A, Garcia Rodriguez LA, Lopez-Ridaura R (2003) Effects of non-steroidal anti-inflammatory drugs on cancer sites other than the colon and rectum: a meta-analysis. BMC Cancer 3: 28

Greaves MF, Maia AT, Wiemels JL, Ford AM (2003) Leukemia in twins: lessons in natural history. Blood 102: 2321-2333

Greaves MF, Wiemels J (2003) Origins of chromosome translocations in childhood leukaemia. Nat Rev Cancer 3: 639-649

Kasum CM, Blair CK, Folsom AR, Ross JA (2003) Non-steroidal antiinflammatory drug use and risk of adult leukemia. Cancer Epidemiol Biomarkers Prev 12: 534-537 
Kozer E, Nikfar S, Costei A, Boskovic R, Nulman I, Koren G (2002) Aspirin consumption during the first trimester of pregnancy and congenital anomalies: a meta-analysis. Am J Obstet Gynecol 187: 1623-1630

Linabery AM, Ross JA (2008) Trends in childhood cancer incidence in the U.S. (1992-2004). Cancer 112: 416-432

Puumala SE, Spector LG, Robison LL, Bunin GR, Olshan AF, Linabery AM, Roesler MA, Blair CK, Ross JA (2009) Comparability and representativeness of control groups in a case-control study of infant leukemia: a report from the Children's Oncology Group. Am J Epidemiol 170: 379-387

Puumala SE, Spector LG, Wall MM, Robison LL, Heerema NA, Roesler MA, Ross JA (2010) Infant leukemia and parental infertility or its treatment: a Children's Oncology Group report. Hum Reprod 25: $1561-1568$

Ross JA, Severson RK, Pollock BH, Robison LL (1996) Childhood cancer in the United States. A geographical analysis of cases from the Pediatric Cooperative Clinical Trials groups. Cancer 77: 201-207

Ross JA, Spector LG (2006) Cancers in Children. In Cancer Epidemiology and Prevention, Schottenfeld D, Fraumeni JF (eds), 3rd edn, pp 1251-1268. Oxford University Press: Oxford

Schuz J, Weihkopf T, Kaatsch P (2007) Medication use during pregnancy and the risk of childhood cancer in the offspring. Eur J Pediatr 166: $433-441$
Shaw AK, Infante-Rivard C, Morrison HI (2004) Use of medication during pregnancy and risk of childhood leukemia (Canada). Cancer Causes Control 15: 931 - 937

Spector LG, Xie Y, Robison LL, Heerema NA, Hilden JM, Lange B, Felix CA Davies SM, Slavin J, Potter JD, Blair CK, Reaman GH, Ross JA (2005) Maternal diet and infant leukemia: the DNA topoisomerase II inhibitor hypothesis: a report from the children's oncology group. Cancer Epidemiol Biomarkers Prev 14: $651-655$

Taki T, Ida K, Bessho F, Hanada R, Kikuchi A, Yamamoto K, Sako M, Tsuchida M, Seto M, Ueda R, Hayashi Y (1996) Frequency and clinical significance of the $M L L$ gene rearrangements in infant acute leukemia. Leukemia 10: $1303-1307$

Weiss JR, Baker JA, Baer MR, Menezes RJ, Nowell S, Moysich KB (2006) Opposing effects of aspirin and acetaminophen use on risk of adult acute leukemia. Leuk Res 30: 164-169

Wen W, Shu XO, Potter JD, Severson RK, Buckley JD, Reaman GH, Robison LL (2002) Parental medication use and risk of childhood acute lymphoblastic leukemia. Cancer 95: 1786-1794

Werler MM, Mitchell AA, Shapiro S (1989) The relation of aspirin use during the first trimester of pregnancy to congenital cardiac defects. $N$ Engl J Med 321: $1639-1642$ 